\title{
"AS FERRAMENTAS DO SINHÔ NUNCA VÃO DERRUBAR A CASA GRANDE": ANÁLISE DISCURSIVA DE UMA TRADUÇÃO MARGINAL
}

\author{
“LAS herramientas del AMO NUNCA desmontarán la CASA del amo": ANÁlisis \\ DISCURSIVO DE UNA TRADUCCIÓN MARGINAL
}

\author{
“The master's Tool will Never Dismantle the Master's House”: Discourse \\ Analysis of a Marginal Translation
}

\section{Roberta Calixto}

Doutoranda em Letras/Linguística, Universidade do Estado do Rio de Janeiro, RJ, Brasil.

Professora visitante, coordenadora pedagógica, Escola Latino Americana de História Política, ELAHP, Brasil. robertasc.santos@gmail.com http://orcid.

org/0000-0002-5423-1811

\section{Luisa Araujo Peixoto}

Mestra em Relações Étnico-Raciais pelo Centro Federal de Educação Tecnológica Celso Suckow da Fonseca (CEFET), RJ, Brasil

0.lvisa.peixoto.0@gmail.com https://orcid.

org/0000-0001-7293-9410

\section{Luciana de Mesquita Silva}

Doutora em Letras, Estudos da Linguagem, Pontifícia Universidade Católica do Rio de Janeiro, Brasil. Docente de Língua Inglesa e Língua Portuguesa no Mestrado em Relações Étnico-Raciais, Centro Federal de Educação Tecnológica Celso Suckow da Fonseca (CEFET), RJ, Brasil. luciana.silva@cefet-ri.br https://orcid. org/0000-0002-5239-8079

\section{Maria Cristina Giorgi}

Doutora em Letras, Universidade

\begin{abstract}
RESUMO
Em conferência intitulada “The Master's Tool Will Never Dismantle The Master's House" (1984), a escritora afro-americana Audre Lorde declara ser preciso forjar novas ferramentas que contribuam para a desconstrução do racismo que, historicamente, subalterniza diversos grupos sociais. Partindo dessa proposta, utilizamos o referencial da Análise do Discurso de Maingueneau e Bakhtin, especialmente a linguagem-intervenção, e o conceito de Bassnett e Lefevere de tradução como reescrita para refletir sobre os efeitos de subjetividade em traduções que, por serem produzidas por pessoas que fazem parte de grupos marginalizados, têm a possibilidade de subverter a lógica das traduções realizadas por grandes editoras. Dessa forma, analisamos a tradução do referido discurso de Lorde para a língua portuguesa feita por Tatiana Nascimento - mulher, negra e lésbica - com o objetivo discutir novas possibilidades de construção de realidades e subjetividades que podem ser produzidas a partir do que chamamos "traduções marginais".
\end{abstract}

Palavras-chave: linguagem-intervenção; literatura afro-diaspórica; traduções marginais; mulheres negras; racismo.

\section{RESUMEN}

En la conferencia titulada “The Master's Tool Will Never Dismantle The Master's House" (1984), la escritora afroestadounidense Audre Lorde afirma que es imperativo crear nuevas herramientas que contribuyan a la deconstrucción del racismo que, históricamente, subalterniza a diversos grupos sociales. Partiendo de esa propuesta, utilizamos como referencia el análisis del discurso de Maingueneau y Bajtín, especialmente el lenguaje-intervención de Rocha, y nos apoyamos en el concepto de Bassnett y Lefevere de la traducción como reescritura para reflexionar sobre los efectos de la subjetividad en las traducciones que, al ser producidas por personas pertenecientes a grupos marginados, tienen la posibilidad de subvertir la lógica de las traducciones realizadas por grandes casas editoras. De esa manera, analizamos la traducción al portugués del discurso referido de Lorde a cargo de Tatiana Nascimento - mujer, negra y lesbiana-, con el objetivo de discutir nuevas posibilidades de construcción de realidades y subjetividades que pueden producirse a partir de lo que llamamos "traducciones marginales".

Recebido : 2020-05-19 / Aceito : 2020-08-11 / Publicado: 2021-05-05

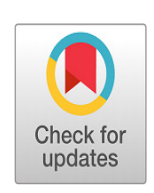


Federal Fluminense, RJ, Brasil. Professora titular, Centro Federal de Educação Tecnológica Celso Suckow da Fonseca (CEFET), RJ, Brasil. cristinagiorgi@gmail.com https://orcid. org/0000-0001-5347-6115
O presente trabalho foi realizado com apoio do Conselho Nacional de Desenvolvimento Científico e Tecnológico (CNPq) no período de 04/2020 a 04/2023. Processo: 310326/2019-2
Palabras clave: lenguaje-intervención; literatura afrodiaspórica; traducciones marginales; mujeres negras; racismo.

\section{Abstract}

In her conference entitled “The Master's Tool Will Never Dismantle The Master's House" (1984), Afro-American writer Audre Lorde argues that we need to create new tools to help deconstruct racism, which has subalternized various social groups throughout history. Drawing from this approach, we take as a reference Maingueneau and Bakhtin's discourse analysis, specifically Rocha's language-intervention, and rely on Bassnett and Lefevere's notion of translation as rewriting in order to reflect upon the effects of subjectivity in translations. According to these, when rendered by individuals belonging to marginalized groups, translations may be prone to subverting the rationale of translations delivered by big publishing houses. Thus, we analyze Lorde's referred discourse, which was translated to Portuguese by Tatiana Nascimento —-someone who was characterized as female, Black, and Lesbian-. The aim is to discuss new possibilities of building fresh realities and subjectivities which can be produced from the so-called "marginalized translations".

Keywords: language-intervention; Afro-diasporic literature; marginalized translations; Black women; racism. 


\section{Considerações iniciais}

Não posso matar o meu texto com a arma do outro. Vou é minar a arma do outro com todos os elementos possiveis do meu texto. Invento outro texto. Interfiro, desescrevo para que conquiste a partir do instrumento de escrita um texto escrito meu, da minha identidade.

Manuel Rui

Nesse pequeno fragmento de Manuel Rui, o escritor angolano traz à tona, em forma de poesia, um posicionamento que é também de muitos outros autores e sobre o qual muitas pesquisas têm-se dedicado a direcionar seus esforços a uma perspectiva de sociedade que considera a linguagem como um dos elementos centrais para a dominação do pensamento do sujeito colonizado (Césaire, 1978; Fanon, 2008; hooks, 2013; Mbembe, 2018). Uma das principais ferramentas na construção de uma realidade em que está bem definida a diferença entre quem tem algum valor e quem não tem, quem pode falar e quem não pode, quem deve viver e quem deve morrer, a linguagem vem sendo utilizada continuamente para reiterar essa distância e manter os grupos subalternizados no lugar a eles designado. Essa prática, que se vê em todas as dimensões do uso da língua, funciona de forma excepcional na (não) publicação e (não) tradução de determinados livros e textos, processos que não são acessíveis a todos os grupos sociais, a despeito (ou, exatamente por esse motivo) de sua importância na validação da produção de conhecimentos.

Contudo, partindo das concepções foucaultianas a respeito do poder e de sua operação, compreendemos que o poder é relacional e também um elemento que está constantemente em disputa. Exatamente por isso, frequentemente nos deparamos com o apelo de autores tais como as intelectuais afro-americanas Patricia Hill Collins (2018), Audre Lorde (2018a) e bell hooks (2013) que, do mesmo modo que Manuel Rui em seu poema, buscam transformar essa linguagem, que inicialmente foi imposta e utilizada como ferramenta de dominação, em ferramenta de resistência a partir de sua transformação em algo próprio. Vemos, dessa forma, que a linguagem é um elemento chave no processo de libertação de corpos e mentes colonizados por meio de epistemologias outras que partam de lugares historicamente subordinados.

A partir dessa lógica, surgem não apenas novas possibilidades de escrita, mas também de tradução, como é o caso do texto "As ferramentas do sinhô nunca vão derrubar a casa-grande", uma tradução do discurso "The Master's Tool Will Never Dismantle The Master's House", de Audre Lorde, proferido em 1984 no âmbito de uma conferência feminista na universidade de Nova York, que analisamos discursivamente no presente artigo. Optamos por abordar essa tradução, realizada por Tatiana Nascimento e publicada no site "Traduzidas", no intuito de refletir sobre como traduções como essa, que denominamos de "traduções marginais", por seu próprio caráter de subversão da lógica econômica e, muitas vezes, seu envolvimento com movimentos sociais, podem apresentar novas possibilidades, resultando em produtos diferentes daqueles que convencionalmente são promovidos pelas editoras, ou mesmo por tradutores que, estando dentro do contexto da academia, estão descolados do debate da desconstrução das estruturas de poder hegemônicas.

Desse modo, aproximando os Estudos de Tradução aos Estudos da Linguagem, recorremos à concepção de dialogismo de Bakhtin (2003[1979]; 2009[1929]), que nos permite compreender que os enunciados contêm em si mesmos a capacidade de estabelecer diálogos com outros enunciados que vieram antes ou que virão depois dele. A relevância da utilização desse conceito dentro de nossa análise sobre a tradução justifica-se na medida em que, uma vez que se compreende não haver uma equivalência completa entre significados nas diferentes culturas, a análise discursiva de uma tradução passa também por analisar marcas discursivas decorrentes das escolhas de palavras do tradutor.

Apropriamo-nos, ainda, dos conceitos de interdiscurso e semântica global de Maingueneau (2005). $\mathrm{O}$ interdiscurso nos serve como orientação 
metodológica, uma vez que a partir de suas diretrizes é possível evidenciar as muitas posições em disputa dentro dos estudos da tradução, campo que, à primeira vista, pode parecer pequeno e coeso. Consequentemente, o conceito nos possibilita estabelecer o recorte de nosso espaço discursivo parte da tríade formada por universo discursivo, campo discursivo e espaço discursivo - de análise: as traduções marginais. Por fim, a semântica global nos traz a noção de que o interdiscurso é, a todo tempo, limitado por um sistema de coerções semânticas que atravessa todos os planos do discurso - desde o vocabulário até a temática - o que nos permite, dentro do campo da tradução, tecer uma análise que seja mais ampla do que a mera materialidade do texto escrito, mas que considere também o contexto da tradução e da subjetividade do tradutor como partes importantes das escolhas feitas pelo tradutor em seu produto final.

A partir desses referenciais teóricos, teceremos considerações acerca do espaço discursivo sobre o qual concentramos nossas análises e que nomeamos "traduções marginais", por serem produzidas em contextos alternativos ao grande mercado editorial, conforme afirmamos anteriormente. São essas formações discursivas que usamos como referência em relação aos demais discursos do campo da tradução para levantar reflexões sobre as produções de sentidos e, consequentemente, de realidades possíveis a partir da existência desses tipos de tradução.

Nesse sentido, dividimos o artigo em três partes: na primeira, tratamos da linguagem como intervenção e de seus atravessamentos de poder na manutenção do racismo estrutural, além da influência tanto da linguagem quanto do racismo nas relações de poder no mercado editorial brasileiro. $\mathrm{Na}$ segunda parte, aprofundamos o referencial teórico sobre tradução, especialmente o debate sobre poder e tradução e sobre tradução como reescrita. Por fim, apresentamos nossa análise discursiva da tradução do discurso de Audre Lorde feita por Tatiana Nascimento (2018b).

\section{"Ferramentas de um patriarcado racista são usadas para examinar os frutos desse mesmo patriarcado "': linguagem, poder e questões étnico-raciais}

A linguagem é tão preponderante nos contextos coloniais que o próprio conceito de raça, por exemplo, é apresentado por Stuart Hall (1995) como um "significante" ou uma "construção discursiva". Ao fazer essa afirmação, Hall delimita raça como elemento pertencente ao campo da linguagem. Isso significa também dizer que ela faz parte de um sistema de classificações e de produção de sentidos cujas origens são múltiplas e estão vinculadas a diferentes culturas e contextos histórico-sociais; algo que não pode ter significado fixo em quaisquer dimensões, sejam elas geográficas, culturais, sociais, históricas e temporais. Entretanto, apesar de suas características não-essenciais, é explícito para Hall que "raça é um dos principais conceitos que organizam os grandes sistemas classificatórios da diferença que operam em sociedades humanas".

Como Sueli Carneiro (2005), entendemos por epistemicídio o conceito cunhado por Boaventura de Sousa Santos no intuito de discutir a destruição, pela cultura do Ocidente branco, de formas de conhecimento e culturas que não são por ele assimiladas. Sua dinâmica de produção tem se dado através da negação sistemática aos sujeitos negros de sua condição de sujeitos de conhecimento, seja nos instrumentos pedagógicos ou nas relações sociais no cotidiano escolar. É recorrente a deslegitimação dos saberes dos negros sobre si mesmos e sobre o mundo, pela desvalorização, negação ou ocultamento das contribuições do continente africano ao patrimônio cultural da humanidade, pela indução ou promoção do embranquecimento cultural, etc.

No caso do Brasil, um país em que o racismo fez parte do passado e faz, de forma crescente,

1 Os subtítulos das seções são trechos da tradução de Tatiana Nascimento analisada neste artigo. 
parte do presente, não é surpresa nos depararmos com práticas de apagamento da população negra em todas as esferas sociais. Especificamente no campo da literatura, debates sobre o silenciamento, o epistemicídio e seus efeitos (Cuti, 2010; Silva, 2014; Carneiro, 2005) têm se tornado cada vez mais recorrentes. Também não é surpreendente que, até os dias atuais, editoras se utilizem de justificativas como "baixa procura" como pretexto para o número reduzido de autoras e autores negras/os publicados por elas, bem como as baixas tiragens que elas propõem a esses escritores. Esse argumento, no entanto, não se sustenta quando confrontado com, por exemplo, a última Festa Literária Internacional de Paraty (a FLIP 2019), que teve quatro autores negros entre os cinco mais vendidos - sendo o quinto um autor indígena, brasileiro do povo Krenak. ${ }^{2}$ Num levantamento das não-traduções, por parte das editoras, de diversos pensadores importantes da diáspora africana, associadas à histórica negação do acesso à educação à parcela negra e mais pobre de nossa população, é possível compreender o tamanho do prejuízo gerado para nossas/os pesquisadoras/es brasileiros/ as na construção de um pensamento que ultrapasse as fronteiras do pensamento moderno/colonizado/ europeu.

No entanto, há cada vez mais experiências de tradução que destoam desse cenário, fugindo à lógica empresarial das editoras, dos contratos de direitos autorais e dos lançamentos em livrarias. Dentre outras denominações, podem ser chamadas de "traduções clandestinas", "traduções livres" ou "traduções sociais" (Mathias, 2017). Neste artigo, optamos pelo termo "traduções marginais", por acreditarmos que este expressa melhor não somente seu caráter transgressor, que põe em xeque a lógica de poder tradicionalmente estabelecida, mas também o local de onde parte a tradutora/o tradutor: as margens.

2 Disponível em: <https://oglobo.globo.com/celina/ dos-5-autores-mais-vendidos-da-flip-4-sao-negros-1-indigena-quem-sao-eles-por-que-isso-tao-revolucionario-23809609>. Acesso em 20 julho 2019.
Feitas de forma independente ou como parte do trabalho de organizações e coletivos, as traduções marginais são iniciativas que têm por objetivo tornar um texto acessível para um determinado público. As motivações podem ser políticas, educacionais, ou mesmo pessoais, quando há o desejo de promover determinado autor ou obra para os falantes da língua-alvo: são traduções impulsionadas pela necessidade. É o caso da tradução de Women, Race, \& Class, de Angela Davis, feita pelo coletivo negro português Plataforma Gueto, em 2013, para a língua portuguesa a partir da publicação bretã, lançada em 1982, pela Women's Press, tendo sido, até a publicação de Mulheres, raça e classe (2016) pela editora Boitempo, a publicação que possibilitou que o livro se tornasse acessível a leitores brasileiros.

Independentes da lógica mercadológica, já que são feitas normalmente sem fins lucrativos e disponibilizadas gratuitamente, essas traduções marginais rompem com os limites estabelecidos pela patronagem $^{3}$, muitas vezes disseminando perspectivas de autores de grupos subalternos - oriundos de países de terceiro mundo, negros e negras, LGBTs, entre outros. Um dos fatores que podem ter contribuído para o impulsionamento desse tipo de tradução foi, como apontado por Mathias (2017), a entrada de mais estudantes negros e, especialmente, de mais estudantes negras, nas universidades brasileiras, interessadas no fato de que esses conhecimentos passassem a estar disponíveis dentro de grupos de estudos nas instituições de ensino.

Esse cenário de resistência construído pelas traduções marginais remete-nos às palavras de Cuti (2010, p. 47), a respeito da relação entre produção de discursos e mecanismos de poder: "os discursos (todos) passam pelo poder dizê-lo. O silêncio pertence à maioria que ouve e, quando muito, repete. Falar e ser ouvido é um ato de poder. Escrever e

3 Conceito desenvolvido por André Lefevere e entendido como: "os poderes (pessoas, instituições) que auxiliam ou impedem a escrita, a leitura e a reescrita da literatura” (Lefevere, 1985 apud Martins, 2010, p. 64). 
ser lido, também”. Não por acaso, o racismo sempre passou pelo silenciar, pelo controle da voz do negro, física e metaforicamente (Kilomba, 2019). Em uma sociedade em que o poder tem cor, isso se reflete em quem tem o poder de dizer, e não seria diferente na literatura nem no mercado editorial como um todo.

Quando falamos de literatura, é muito comum que o façamos partindo de uma noção de gosto ou escolha pessoal - aquela que o leitor hipotético fará ao olhar capas em uma livraria, ou ler sinopses em um site. No entanto, essa escolha só pode ser feita dentro de um universo de materiais já publicados, já existentes como produto. E, mais do que isso, que pertençam ao universo de obras que chegam às mãos desse leitor hipotético, literal ou virtualmente, para poder ser apreciadas, selecionadas, rejeitadas. Até isso acontecer, vários filtros diferentes (Cuti, 2010) já foram postos em ação, fazendo a mediação entre o que é criado e o que é lido. Pensando nas etapas pelas quais um livro passa, da idealização às mãos do leitor, identificamos quatro séries principais de filtros: a primeira, de escrita; a segunda, de publicação; a terceira, de leitura; a quarta, de tradução.

A primeira diz respeito a quem, numa sociedade como a nossa, chega a escrever um livro. Partindo do princípio de que se comunicar e ter histórias para contar é essencialmente humano, podemos questionar então por que apenas algumas pessoas chegariam a fazê-lo sob a forma escrita, seja ficção ou não-ficção. Se sem um contexto as respostas ficariam limitadas a alguma variação que se aproxima de "talento" ou "vontade", quando se acrescenta o cenário de um país como o Brasil, o número de filtros se amplia: Quem sabe ler e escrever? Quem tem contato com livros e literatura? Quem tem tempo para pensar em criar algo para além da própria sobrevivência? Em um país em que a educação foi e é constantemente negada à população negra, não é difícil adivinhar que as respostas para essas perguntas tenham uma cor específica.

Na série localizada entre escrever e publicar, os filtros que se apresentam para a escolha do que será ou não publicado são os do mercado editorial, o qual se baseia em critérios pré-existentes de comercialização e "qualidade", além de adequação à linha editorial ${ }^{4}$. Agem aqui as modas então vigentes, as análises críticas da academia, as apostas em tendências futuras, toda uma estratégia de mercado, além do gosto pessoal do editor. É importante que se observem esses filtros de forma mais profunda, porque publicar também pode significar dizer quem merece ser ouvido. No Brasil, nunca se disfarçou que quem "merece" ser ouvido é homem, branco, heterossexual. Os filtros sociais estão ali, funcionando juntamente com todos os outros que dizem respeito, a princípio, apenas a "mercado" ou "qualidade". A terceira série de filtros funciona porque para ser lido não basta ser publicado. É refletindo sobre o poder e a forma como se dá o seu exercício dentro do campo literário que Cuti (2010, p. 48) traz à tona o conceito de "valor da obra”, que se pode entender como a classificação pela qual uma obra passa, e que justifica a sua seleção para que ela seja lida por uma ou muitas pessoas, a depender da situação para a qual está sendo selecionada. Seja em uma aula, um concurso ou no lazer, o autor ressalta que a literatura é um tipo de discurso que está altamente relacionado à nossa vida cotidiana, mas que também passa por diversos processos de "filtragem": o professor, a banca de seleção ou mesmo a livraria ou o atendente da loja. Dalcastagnè destaca essa questão ao falar da ampliação de espaços que a literatura negra produzida no Brasil vem conquistando. Conforme a autora,

Sem dúvida, houve uma ampliação de espaços de publicação, seja nas grandes editoras comerciais, seja a partir de pequenas casas editoriais, em edições pagas, blogs, sites, etc. Isso não quer dizer que esses espaços sejam valorados da mesma forma. Afinal, publicar um livro não transforma ninguém em escritor, ou seja, alguém que está nas livrarias, nas resenhas de jornais e revistas, nas listas dos premiados dos concursos literários, nos programas das disciplinas, nas prateleiras das

4 Entendemos linha editorial como o conjunto de parâmetros (que envolvem gênero, temática, formato, público-alvo) que definem o que pode ser publicado por uma determinada editora, a partir da identidade e estratégias mercadológicas assumidas por ela. 
bibliotecas. Basta observar quem são os autores que estão contemplados em vários dos itens citados, como são parecidos entre si, como pertencem a uma mesma classe social, quando não tem as mesmas profissões, vivem nas mesmas cidades, tem a mesma cor, o mesmo sexo [...] (Dalcastagnè, 2012, p. 14)

Quando se pesam todas as micro-decisões presentes nesse processo, fica fácil perceber como as disputas de poder presentes em todos os âmbitos da sociedade também participam dele, e como a editora não decide sozinha quem vai ser lido ou não. No entanto, também é fácil visualizar que as editoras dominam uma etapa chave nessa trajetória, mesmo quando se considera a dispersão promovida pela internet. Sim, já é muito mais fácil "publicar", uma vez que a palavra pode se referir, hoje, tanto ao que é impresso e comercializado pelas editoras quanto ao que circula em redes sociais digitais com pouca ou nenhuma intervenção em relação à ideia original, além de todas as possibilidades intermediárias entre uma coisa $\mathrm{e}$ outra. As editoras, contudo, ainda detêm os meios de produção do objeto que simboliza o conhecimento por excelência, o que significa que seus produtos e as "verdades" que eles propagam são elementos centrais para a manutenção do regime de verdade (Foucault, 2013) em vigência.

As editoras protagonizam, ainda, uma quarta rede de filtros, quando há a transposição de uma obra de um país para outro cujas línguas oficiais são diferentes. Deve-se ter em conta que esses livros já passaram pelas outras três etapas para serem publicados e lidos em seus países de origem. E agora, passam por mais uma: a seleção do que vale a pena ser transportado de uma cultura para outra, de uma língua para outra, via tradução. Ter que passar por essa quarta barreira não diminui, necessariamente, o valor social da obra, uma vez que muitas vezes, em países como o Brasil, acontece justamente o contrário. A questão aqui é, novamente, quem vai passar por esses filtros e chegar ao mercado editorial brasileiro.

O mesmo tipo de bloqueio social que ocorre com relação a autores nacionais (de gênero e raça, por exemplo) incide no momento em que se deve selecionar o que vai ser ou não ser traduzido. Dennys Silva-Reis e Lauro Maia Amorim (2016) discutem acerca da tradução de literatura negra e do trabalho realizado por tradutores negros, indicando que muitos autores estrangeiros negros importantes deixam de ser traduzidos para o português brasileiro. É o caso de nomes como June Jordan, Toni Cade Bambara e Nikki Giovanni, que são parte importante do pensamento feminista negro, e continuam sem nenhuma tradução oficial no país. Audre Lorde, por exemplo, teve a primeira tradução de uma de suas obras - intitulada Irmã outsider: ensaios e conferências - publicada pela editora Autêntica apenas em dezembro de 2019, 27 anos após sua morte. D’Ambrosio, citado por Silva-Reis e Amorim (2016), traz diversos possíveis motivos para que isso ocorra:

\footnotetext{
O número de livros importantes não traduzidos para o português é significativo. As razões são muitas. Incluem a especificidade de obras para públicos muito restritos, o desconhecimento pelas editoras nacionais de textos essenciais no panorama da literatura mundial e a ausência de editoras especializadas para publicar obras de difícil tradução pelas peculiaridades da língua ou do estilo do autor. (d'Ambrosio, sd/sp apud Silva-Reis; Amorim, 2016, p. 8)
}

Várias dessas justificativas passam pelo racismo, esteja ele impactando o interesse do público, a formação dos tradutores, o desconhecimento ou desinteresse das editoras. O argumento do mercado restrito, entretanto, se sustenta cada vez menos: isso pode ser notado quando pensamos que Angela Davis, que lotou um auditório da UFBA em 2017, só teve seu livro Women, Race, \& Class traduzido pela editora Boitempo pouco tempo antes, em 2016, 35 anos após ser publicado pela primeira vez, nos Estados Unidos - e segue sendo uma das obras com o maior número de vendas no âmbito da editora em questão desde o seu lançamento. Cabe ressaltar ainda que os demais livros da autora, lançados posteriormente, também estão, segundo a própria editora, entre os 10 livros mais vendidos. A publicação de obras traduzidas, tais como as de Angela Davis, demonstram como a tradução é um processo complexo que envolve não apenas 
fatores linguísticos, mas também culturais, ideológicos, mercadológicos, entre outros. $\mathrm{Na}$ seção seguinte, trataremos mais especificamente sobre esse assunto.

\section{"Sabemos que a sobrevivência não é uma habilidade acadêmica": tradução como um processo de reescrita}

Adentramos o campo dos estudos da tradução utilizando como base a visão sobre poder e tradução de André Lefevere e Susan Bassnett (1990), segundo os quais a tradução é uma forma de reescrita e "[...] como todas as (re)escritas nunca é inocente. Há sempre um contexto em que a tradução ocorre, sempre uma história da qual um texto emerge e para a qual um texto é transposto" (Bassnett e Lefevere, 1990, p. 11). Nesse sentido, Adélia Mathias (2017) ressalta a importância de traduções feitas por grupos de estudantes universitários negros que produzem traduções não-oficiais de textos que os apoiam no embasamento teórico de suas formulações raciais, temáticas até então pouco abordadas dentro da academia, e o significativo papel que elas cumprem na formulação de novas epistemes e de novas identidades. Mathias também destaca que ainda que não cumpram todos os trâmites necessários para serem consideradas "traduções oficiais”, elas exercem uma função relevante e necessária de resistência ao racismo epistêmico na academia.

Como podemos ver por este exemplo, há muitas relações que atravessam e modificam o caráter das traduções, o que nos dá base para contrapor a suposta neutralidade da tradução.

Cada palavra, aplicada a seu contexto linguístico-cultural, possibilita a construção de sentidos que nem sempre são compartilhados com pessoas pertencentes a outras culturas, ou mesmo às mesmas culturas. Dessa forma, os textos dos enunciadores das línguas fonte e meta estão repletos de marcas que não estão isoladas de seus próprios sistemas culturais. É justamente com base nessas premissas, por exemplo, que foi possível a Branco e Maia (2016) produzir reflexões sobre as assimetrias culturais que são produzidas no exercício da tradução, sobretudo em contextos de colonização, que se aproximam bastante do conceito de linguagem-intervenção (Rocha, 2006), segundo a qual o discurso não descreve uma mera representação do mundo; é um meio de intervenção e invenção desse mundo que produz formas de vida e subjetividades.

Pautada no pensamento de Lefevere, Tatiana Nascimento (2014) extrapola a preponderância cultural no processo tradutório: ela busca deixar explícito o papel fundamental que o tradutor e sua formação como sujeito cumprem em toda essa atividade. A autora afirma que a tradução — sendo essa uma reescrita — é “[...] feita por alguém, feita desde algum lugar, algum contexto político, histórico, étnico, sexual, generado" (Nascimento, 2014, p. 20).

Essa visão de tradução fica bastante evidente em seu artigo "Quem nomeou essas mulheres 'de cor’? Políticas feministas de tradução que mal dão conta das sujeitas negras traduzidas" (Nascimento, 2017), em que a autora analisa uma tradução do texto de Kia Lilly Caldwell intitulado "Racialized Boundaries: Women's Studies and the Question of 'Difference' in Brazil", que foi traduzido como "Fronteiras da diferença: raça e mulher no Brasil" (2000) para o português e publicado na revista acadêmica brasileira Estudos Feministas. É importante destacar que não há qualquer tipo de menção sobre quem traduziu o referido texto.

A análise de Nascimento gira em torno da expressão “mulheres não-brancas", tradução proposta para "women of color", que apaga o fato de esse ter sido um termo escolhido por uma geração de mulheres de ascendência asiática, latino-americana, indígena e africana, no contexto dos Estados Unidos, para se autodefinirem (Collins, 2018). Numa pretensa tentativa de evitar o estranhamento que geraria o uso da expressão "mulheres de cor", há a escolha de um termo que não existe no Brasil, e que pode não apenas gerar um desconforto da mesma forma, como também esvazia "women of color" de sua 
significação política. Ironicamente, e com destaque para o anonimato do/a tradutor/a do texto, o artigo de Nascimento aponta que, se o texto-fonte enfatiza que "é preciso dar um maior enfoque para 'diferença' racial e para as relações entre raça e gênero” (Nascimento, 2017, p. 91), não é possível perceber essa preocupação na tradução do texto. Em contraposição à tradução de "women of color" como "mulheres não-brancas", Nascimento, por sua vez, defende o uso do termo "mulheres de cor", utilizado pelo movimento negro brasileiro nos anos 40 e 50 do século xx com o objetivo de ressignificar positivamente uma expressão historicamente negativa em relação aos negros.

É justamente nessa compreensão - de que a tradução é fruto do meio social no qual estão inseridos o tradutor e o próprio processo tradução- que nos debruçamos para compreender que produtos são esses que surgem de processos que não obedecem a lógicas mercadológicas e nos quais, quase sempre, os sujeitos que traduzem estão identificados de alguma maneira com os sujeitos traduzidos. Justamente por isso, interessa-nos perceber de que modo essas/es tradutoras/es fazem uso da língua em seus processos de tradução e quais relações dialógicas estabelecem em contextos altamente colonialistas como os existentes no Brasil. Também nos interessa investigar como o "aparecimento" dessas traduções marginais cria novas relações dialógicas que reforçam positivamente subjetividades historicamente subalternizadas. Nesse sentido, para ilustrar essa ideia, na próxima seção pretendemos investigar como a própria Tatiana Nascimento lidou com os desafios de traduzir um discurso de Audre Lorde (2018b) para a língua portuguesa.

\section{"Nossas filhas é que estão na pista": tradução das margens para as margens}

Ao aliar os estudos da tradução aos do discurso, deparamo-nos com muitos desafios. Ao optarmos pela abordagem linguística como metodologia de análise, devemos considerar uma série de pressuposições analíticas, dentre elas o primado do interdiscurso, que é a hipótese criada por Maingueneau (2005) como proposta de abordagem para lidar com a heterogeneidade dos discursos. Essa heterogeneidade, para os linguistas, é parte constitutiva e indissociável dos discursos, de modo que, é sempre possível recuperar discursos outros que são intrínsecos ao próprio enunciado. No caso das traduções, o próprio conceito de interdiscursividade traz à tona algumas questões: sabemos que uma tradução consiste na transposição de um texto de uma cultura a outra. Esse é um processo extremamente complexo no qual há, pelo menos, dois sujeitos explicitamente envolvidos - traduzida/o e tradutor/a. Ou seja, a interdiscursividade, neste caso, poderia [ou deveria] ser considerada como "heterogeneidade 'mostrada'” (Maingueneau, 2005, p. 33).

Se numa perspectiva do senso comum, essa relação não é evidente, dentro do campo da análise discursiva, é preciso considerar não apenas as/os sujeitas/os nesta relação traduzido/a-tradutor/a, mas também as subjetividades que as/os atravessam. Dessa forma, como analisar as traduções, uma vez que existe um Outro [tradutor/a] que, dentro de um campo majoritário acadêmico, deve se apagar em função de um suposto texto original ? É possível eliminar-se completamente de um discurso? Como evidenciar o trabalho do/a tradutor/a, quando seu trabalho é justamente trazer a voz do Outro? Qual a influência do Outro-tradutor no processo de tradução? Quais são os efeitos dessas traduções na construção de outras subjetividades?

Ao tomar como base a interdiscursividade, Maingueneau estabelece ferramentas metodológicas de análise discursiva que ajudam a decompor a interdiscursividade em universo discursivo, campo discursivo e espaço discursivo. O universo discursivo é descrito como o "conjunto de formações discursivas de todos os tipos que interagem numa conjuntura dada" (Maingueneau, 2005, p. 35). O universo discursivo, apesar de limitado, é ainda muito vasto para que um analista do discurso consiga realizar seu trabalho. Dessa forma, delimita-se o campo discursivo, que se refere às formações discursivas que, dentro de um universo discursivo, 
estão em concorrência por referirem-se a um mesmo assunto. Essa concorrência não pode ser entendida somente como um conflito explícito, mas também como enunciados que concordam ou que se põem em neutralidade aparente em relação a determinado assunto. É no interior do campo discursivo que se pode perceber a formação dos discursos e a influência que exercem uns sobre os outros. Evidentemente, como citamos anteriormente, é preciso considerar que esses discursos operam a partir de uma lógica hierárquica instável que "opõe discursos dominantes e dominados e eles não se situam todos necessariamente no mesmo plano" (Maingueneau, 2005, p. 37). Refinando ainda mais os critérios de análise, Maingueneau chega por fim aos espaços discursivos, descritos como o "subconjunto de formações discursivas que o analista julga relevante para seu propósito colocar em relação" (Maingueneau, 2005, p. 37). As formações discursivas, por sua vez são, como definido por Foucault (2000), uma convenção que se constrói

\section{0} a partir de enunciados semelhantes em conceitos e temáticas, sobre os quais possa se traçar uma regularidade discursiva - de correlações, de posições, de funcionamento, entre outros.

Com esses pressupostos teóricos, avançamos sobre o campo discursivo das traduções e ressaltamos neste artigo uma formação discursiva que, dentro deste campo, se contrapõe a uma concepção amplamente aceita pelo senso comum de que a tradução seria uma espécie de transposição ipsis litteris de um texto escrito em uma língua para outra, como mencionamos anteriormente. Interessanos o conceito de semântica global, proposto por Maingueneau (2005) no intuito de melhor operacionalizar análises. O referido conceito nos permite entender que, em um texto, forma e conteúdo não estão dissociados e se relacionam em todos os planos discursivos - vocabulário, modos de enunciar, dêixis, temas - construindo significados que se materializam no texto. $\mathrm{O}$ trabalho do analista é buscar indícios nesse texto que o remetam a determinada prática discursiva. Dito de outro modo, a noção de semântica global tem como ponto de partida uma zona de regularidade semântica que pressupõe regularidades globais às quais estão submetidos léxico, temática, modo de enunciação e de organização da comunidade que enuncia o discurso. E tais restrições em cada formação discursiva - em cada contexto linguístico - delimitam critérios do que pode e não pode nela ser enunciado (Maingueneau, 2005).

O texto "The Master's Tools Will Never Dismantle The Master's House" (Lorde, 1984), é a transcrição do discurso de Audre Lorde em uma conferência do New York University Institute for the Humanities. "Preta, lésbica, guerreira e poeta", como costumava se definir, a ativista, nascida em 1934, se percebe como uma das pouquíssimas mulheres negras convidadas para falar — na única mesa em que as perspectivas de feministas negras e lésbicas são consideradas.

Tatiana Nascimento disponibiliza a tradução desse texto em seu blog traduzidas.wordpress.com, em cuja página principal aparecem o título diáspora $y$ dissidência sexual em trânsito e, como subtítulo, a frase "escritas negras/de cor feministas lésbicas cuíer/queer traduzidas por tatiana nascimento”. Já na apresentação do blog é explicitado o propósito das traduções: são disponibilizados para o público brasileiro textos de mulheres de cor, especialmente pretas e LGBTI+. Chama a atenção a palavra "cuíer", transcrição no português para a sonoridade da palavra "queer", usada, em inglês, para se referir a diversos grupos de pessoas hétero-dissidentes, além de uma perspectiva teórica, mas que não tem tradução para o português. Assim escrita, a palavra é facilmente pronunciável por falantes de português, mesmo que estes não dominem a língua inglesa, o que desnaturaliza a ideia de que todos os brasileiros seriam proficientes na língua inglesa.

Retiramos, do texto-meta, fragmentos que se destacam por seu diálogo com questões étnico-raciais e de gênero, além de outros que trazem marcas de oralidade, ressaltando escolhas da tradutora sobre as quais falaremos mais adiante. No decorrer 
da análise, traremos quadros com esses destaques lado a lado com os respectivos trechos no texto-fonte.

Em uma primeira leitura do título da tradução, iluminamos duas expressões: a primeira é 'sinhô, como tradução para 'master', que se repete ao longo do corpo do texto-meta, em todas as ocorrências de 'master' no texto-fonte (veja a análise A na Tabela 1). No contexto brasileiro, como se pode encontrar em vários textos literários e novelas de época, por exemplo, o termo dialoga com nosso passado de escravidão - como master dialoga com o passado de escravidão estadunidense-, em que a figura do sinhô era forte como escravizador e dono da 'casa-grande', no texto-fonte, a 'Master's House'. A opção pelo uso da grafia 'sinhố, transcrição literal da pronúncia comumente utilizada pelos escravizados da palavra 'senhor', pode ser compreendida como uma demarcação explícita da posição social da qual enuncia Audre Lorde, e também a própria Tatiana Nascimento, que se define como "tradutora lésbica feminista negra” (Nascimento, 2014, p. 10),

Tabela 1 Análise A

\begin{tabular}{ll}
\hline \multicolumn{1}{c}{ Texto-fonte } & \multicolumn{1}{c}{ Texto-meta } \\
\hline $\begin{array}{l}\text { The Master's Tools Will Never } \\
\text { Dismantle the Master's House }\end{array}$ & $\begin{array}{l}\text { As ferramentas do sinhô nunca } \\
\text { vão derrubar a casa-grande }\end{array}$ \\
& \\
"[...] and without a significant & "[...] e sem uma perspectiva \\
input from poor women, Black & significativa das mulheres \\
and Third World women, and & pobres, Negras e Terceiro- \\
lesbians." & Mundistas, e lésbicas." \\
\hline
\end{tabular}

uma vez que a referida grafia, em lugar de desqualificar, como ocorre em geral, com o escravizado, o aproxima dos interlocutores.

A segunda marca que ressaltamos no texto-meta é a utilização de "mulheres de Cor" para "women of Color”, em vez do insípido "mulheres não-brancas". Com base no já citado artigo de Nascimento (2017), entendemos que o termo dialoga com significados políticos, e com a subjetividade das mulheres de Cor nos Estados Unidos, que são a referência. A expressão "mulheres não-brancas", ao contrário, trata a mulher branca como hegemônica e a negra como "algo que não segue essa norma”, como um "desvio".

Nascimento não apenas recorre à expressão "mulheres de Cor", como também mantém a letra maiúscula da palavra "Cor", utilizada no texto-fonte. Ainda que a língua inglesa tenha um uso muito mais extensivo de maiúsculas do que o português brasileiro - língua na qual, conforme a norma culta, "Cor" não levaria a maiúscula no início - , sinaliza não apenas um dialogismo explícito entre o texto-fonte e o texto-meta, como também um modo de particularizar o termo, no nosso entendimento, de forma positiva, próprio do uso de maiúsculas.

O uso de maiúsculas repete-se em todo o texto, como nos casos de "Negras" e "Terceiro-Mundistas", por exemplo (Tabela 2). Realçamos o termo "Terceiro-Mundistas" - 'Third World women' no texto-fonte, com Third World exercendo função adjetiva para women, e no texto-meta apenas uma palavra composta - que, nesse texto, leva uma maiúscula em cada parte da palavra, indo na contramão dos gentílicos que, normalmente, não levam maiúsculas. Partindo da compreensão de que "terceiro-mundista" é uma designação comum entre mulheres que aderem ao "feminismo pós-colonial", uma possibilidade de leitura, em dialogismo com o contexto político em questão, é o destaque dado à condição de sujeitas dessas mulheres a quem o estatuto de humanidade, ainda hoje, segue sendo negado.

Tabela 2 Análise B

\begin{tabular}{ll}
\hline \multicolumn{1}{c}{ Texto-fonte } & \multicolumn{1}{c}{ Texto-meta } \\
\hline "[...] and without a significant & "[...] e sem uma perspectiva \\
input from poor women, Black & $\begin{array}{l}\text { significativa das mulheres } \\
\text { and Third World women, and } \\
\text { pobres, Negras e Terceiro- } \\
\text { lesbians." }\end{array}$ \\
\hline
\end{tabular}


Marcas que iluminam o comprometimento da tradutora com os movimentos sociais e com as sujeitas traduzidas como as mostradas anteriormente permeiam todo o texto. No uso de "mulheres-identificadas-com-mulheres” (Tabela 3), termo que remonta ao contexto e ao debate político realizado por mulheres durante a segunda onda do movimento feminista ${ }^{5}$, apontamos um explícito diálogo com a história da luta política feminista. Os termos mulheres-identificadas-com-mulheres e mulheres-identificadas-com-homens foram forjados na década de 1970 a fim de diferenciar mulheres que se encaixavam ou não nas definições de feminilidade impostas pela sociedade patriarcal, independentemente de sua orientação sexual.

Tabela 3 Análise C

\begin{tabular}{ll}
\hline \multicolumn{1}{c}{ Texto-fonte } & \multicolumn{1}{c}{ Texto-meta } \\
\hline "In this paper there was no & "Nesse artigo, não houve \\
examination of mutuality & análise da mutualidade entre \\
between women, no systems & mulheres, nem de sistemas \\
of shared support, no & de apoio compartilhado, nem \\
interdependence as exists & da interdependência como há \\
between lesbians and women- & entre lésbicas e mulheres- \\
identified women." & identificadas- com-mulheres." \\
\hline
\end{tabular}

Apesar do desuso em que essa expressão caiu desde a sua formação na década de 1970, ressaltamos que a manutenção da expressão no texto-meta é significativa, posto que a mesma poderia ter sido apagada e, consequentemente, substituída por uma construção mais descritiva. Desse modo, a manutenção dessa expressão permite-nos identificar, também no texto-meta, um alinhamento com a preservação da história da luta das mulheres.

5 Ver tradução marginal de Carol Correia do capítulo 16 do livro Feminism Is for Everybody (2000), de bell hooks, intitulado "Felicidade total - lesbianidade e feminismo". Disponível em: <https://medium.com/@ solemgemeos/cap\%C3\%ADtulo-16-de-feminismo-\%C3\%A9-para-todos-por-bell-hooks-ba4cfcab64b8>. Acesso em 25 de fevereiro de 2020.
Tabela 4 Análise D

\begin{tabular}{ll}
\hline \multicolumn{1}{c}{ Texto-fonte } & \multicolumn{1}{c}{ Texto-meta } \\
\hline $\begin{array}{l}\text { "[...] as well as the courage } \\
\text { and sustenance to act where } \\
\text { there are no charters." }\end{array}$ & $\begin{array}{c}\text { "[...] bem como a coragem e } \\
\text { a sustância para agir quando } \\
\text { não é permitido." }\end{array}$ \\
& "Mulheres pobres e \\
"Poor women and women & $\begin{array}{l}\text { mulheres de Cor sabem } \\
\text { of Color know there is a }\end{array}$ \\
$\begin{array}{l}\text { difference between the daily } \\
\text { manifestations of marital }\end{array}$ & $\begin{array}{l}\text { que há uma diferença entre } \\
\text { as manifestações diárias }\end{array}$ \\
because it is our daughters & de escravização marital e \\
pho line 42nd Street." & filhas é que estão no pista." \\
\hline
\end{tabular}

Destacamos ainda a opção geral por escolhas muito próximas da oralidade. Além do já mencionado "sinhô" destacamos, nos trechos acima, a seleção da palavra feminina "sustância" e não "sustento", em "the courage and sustenance to act where there are no charters", por exemplo. Essa escolha abre um diálogo explícito com a comunidade negra. Seja porque a tradição oral é muito forte na cultura africana, seja porque a forma como as palavras foram grifadas está diretamente relacionada ao imaginário que construímos sobre a pronúncia do português pelos negros escravizados. Outra escolha interessante ocorre em "nossas filhas é que estão na pista", tradução para "it is our daughters who line $42^{\text {nd }}$ Street", frase que traz, no texto-fonte, uma referência de lugar não conhecida do público brasileiro, ao falar de prostituição ${ }^{6}$ (Tabela 4). "Estar na pista” não necessariamente remete à prostituição, contudo, assim como no texto-fonte o contexto permite essa leitura. Dessa forma, podemos ver a preocupação da tradutora em aproximar do contexto do público a quem se destina sua tradução uma expressão que é culturalmente muito

6 Nos anos de 1970, a área em torno da Times Square em Manhattan, Nova York (que inclui a $42^{\text {nd }}$ Street) ficou bastante conhecida como ponto de prostituição. Mais informações: <https://www.nytimes.com/1971/07/09/ archives/most-times-square-prostitutes-staying-off-street-to-avoid-arrest.html>. Acesso em 27 fevereiro 2020. 
localizada, sem, entretanto, apagar a forma coloquial que Lorde opta por utilizar.

Podemos dizer, de forma geral, que a própria existência dessa tradução marginal atende ao chamado de Lorde: temos uma tradutora negra, feminista e lésbica que subverte o universo convencional de tradução e publicação de livros, tão dominados pela lógica das ferramentas do master - ou do "sinhô" - como traz Nascimento, para apresentar uma perspectiva diferente, de uma autora preta e lésbica nunca traduzida no Brasil oficialmente até então. Sendo assim, essa atitude de Nascimento dialoga com a seguinte visão de Collins (2019):

Para além de simples oposição à desigualdade, tradutores/as progressistas frequentemente usam seu lugar social como mediadores/as de poder para construir espaços subversivos e transgressivos entre pessoas que compartilham interesses e línguas diferentes. (Collins, 2019, p. 28)

\section{Considerações finais}

Neste artigo, propusemo-nos a pensar os estudos da tradução a partir da perspectiva discursiva, refletindo acerca da linguagem como um modo não somente de retratar, mas, principalmente de construir realidades, visto que um sujeito, a partir de sua subjetividade, de sua compreensão de mundo, tem a possibilidade de construir sentidos e atribuir significados relativos às suas vivências. Justamente por essa multiplicidade de possibilidades de leitura é impossível falarmos sobre "a realidade", mas somente sobre diversas realidades que surgem a partir das muitas subjetividades existentes. Notadamente, essas subjetividades são, o tempo todo, atravessadas por relações de poder que, em maior ou menor grau, limitam as compreensões dos sujeitos. O racismo estrutural (Almeida, 2018) é um exemplo relevante de fenômeno que se mantém utilizando-se de práticas linguageiras que percorrem todas as esferas sociais, inclusive na tradução, sobre a qual tratamos neste artigo.

Diante desse contexto em que o racismo estrutural opera e "cala" as vozes subalternas, tanto nacionais quanto estrangeiras, as traduções marginais cumprem um papel muito importante ao propagar vozes que, de outra maneira, dificilmente chegariam àqueles que não foram alfabetizados em outros idiomas. Não à toa, Adélia Mathias (2017) compara essas práticas de tradução de autores negros ao quilombismo de Abdias do Nascimento. Nesse sentido, destacamos também que as traduções marginais, ao se afastarem de uma perspectiva mercadológica, podem produzir um tipo de tradução que contém, nela mesma, uma linguagem que não segue as lógicas do poder hegemonicamente estabelecido, produzindo, assim, um duplo rompimento com este status quo, resultado de um processo de colonização que, além de desumanizar as populações negras, sobrevive da sua subalternização no intuito de manter os privilégios do grupo hegemônico.

Por fim, destacamos que as traduções, sobretudo no caso de enunciadoras-mulheres-negras traduzidas por outras mulheres negras, deixam sua contribuição em diversos âmbitos: a começar por seu caráter controverso dentro do campo da tradução, no qual elas recusam o papel da tradutora "invisível", passando pela construção de um repertório epistemológico que auxilia na formação de uma consciência coletiva que atravessa fronteiras. Nesse processo em que mulheres negras falam delas e por elas mesmas, concretiza-se o conceito de autodefinição (Collins, 2018) tão importante para construção do Pensamento Feminista Negro. Entretanto, quando se trata da diversidade defendida por Lorde (1984), essas traduções ajudam a evidenciar que experiências vividas em diversos contextos diferentes têm suas semelhanças e singularidades. Audre Lorde acreditava que "a interdependência entre mulheres é o caminho para uma liberdade que permita ao Eu que exista, não para que seja usado, mas para que seja criativo". Essas traduções marginais nos parecem um potente exemplo das ferramentas que a escritora caribenha-americana acredita que podem derrubar a casa-grande.

\section{Referências}

Almeida, S. L. de (2018). O que é racismo estrutural? Letramento. 
Bakhtin, M. (2003[1979]). Estética da criação verbal. (4. ${ }^{\mathrm{a}}$ ed.; P. Bezerra, Trad.). Martins Fontes.

Bakhtin, M. (2009[1929]). (Volochinóv). Marxismo e filosofia da linguagem: Problemas fundamentais do método sociológico na ciência da linguagem. (13. ${ }^{\mathrm{a}}$ ed.; M. Lahud \& Y. F. Vieira, Trads.). Hucitec.

Bassnett, S., e Lefevere, A. (1990). Introduction: Proust's grandmother and the thousand and one nights: The "cultural turn" in translation studies. Em S. Bassnett e A. Lefevere (Orgs.), Translation, history and culture (pp. 1-13). Pinter Publishers.

Branco, S. de O., e Maia, I. N. B. (2016). O entrelugar da tradução literária: as exigências do mercado editorial e suas implicações na formação de identidades culturais. Ilha do Desterro, 69(1), 213-221. https://doi. org/10.5007/2175-8026.2016v69n1p213

Caldwell, K L. (1999). Ethnographies of identity: (Re)constructing race and gender in contemporary Brazil. (Tese de doutorado), University of Texas, Austin, EUA.

Carneiro, S. A. (2005). A construção do outro como não ser como fundamento do ser. (Tese de doutorado), Universidade de São Paulo, São Paulo, Brasil. https:// negrasoulblog.files.wordpress.com/2016/04/aconstruc3a7c3a3o-do-outro-como-nc3a3o-sercomo-fundamento-do-ser-sueli-carneiro-tese 1.pdf

Césaire, A. (1978). Discurso sobre o colonialismo. Livraria Sá da Costa Editora.

Collins, P. H. (2018). Epistemologia feminista negra. Em J. Bernardino-Costa, N. Maldonado-Torres, e R. Grosfoguel (Orgs.), Decolonialidade e pensamento afrodiaspórico (pp. 139-170; A. C. J. Pereira, Trad.). Autêntica Editora.

Collins, P. H. (2019). Sobre tradução e ativismo intelectual. (C. de G. S. Araújo, D. Silva-Reis, e L. de M. Silva, Trads.). Ártemis, 27(1), 25-32. https://doi. org/10.22478/ufpb.1807-8214.2019v27n1.46697

Cuti. (2010). Autocensura: "eu” negro X “tigre” do silêncio. Em E. de A. Duarte (Org.), Literatura negro-brasileira (pp. 31-46). Selo Negro.

Dalcastagnè, R. (2012). Um mapa de ausências. Literatura brasileira contemporânea: um território contestado (pp. 147-196). UERJ.

Davis, A. (2013). Mulher, raça e classe. (Plataforma Gueto, Tradução Livre). https://we.riseup.net/assets/165852/mulheres-rac3a7a-e-classe.pdf

Fanon, F. (2008). Pele negra, máscaras brancas. (R. da Silveira, Trad.). EDufBA. https://doi. org/10.7476/9788523212148
Foucault, M. (1999). História da sexualidade I: a vontade de

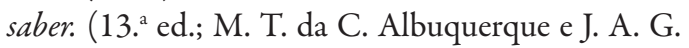
Albuquerque, Trads.). Edições Graal.

Foucault, M. (2000). A arqueologia do saber (6. ${ }^{a}$ ed.; L. F. B. Neves, Trad.). Forense Universitária.

Foucault, M. (2013). Vigiar epunir: nascimento da prisão. Vozes.

Hall, S. (1995). Raça o significado flutuante. h t tp: / / revistazcultural.pacc.ufrj.br / raca-o-significante-flutuante $\% \mathrm{EF} \% 80 \% \mathrm{AA} /$

hooks, b. (2013). A língua: ensinando novos mundos/novas palavras. Ensinando a transgredir: educação como prática da liberdade (pp. 223-233; M. B. Cipolla, Trad.). wMF Martins Fontes.

Kilomba, G. (2019). Memórias da plantação: episódios de racismo cotidiano. Cobogó.

Lefevere, A. (2014). Why waste our time on rewrites? The trouble with interpretation and the role of rewriting in an alternative paradigm. Em T. Hermans (Org.), The manipulation of literature: Studies in literary translation (pp. 215-243). St. Martin's. https://doi. org/10.4324/9781315759029-12

Lorde, A. (1984). Sister outsider: "The master's tool will never dismantle the master's house". Crossing Press.

Lorde, A. (2018a). The master's tools will never dismantle the master's house. Disponível em: https://collectiveliberation.org/wp-content/uploads/2013/01/ Lorde_The_Masters_Tools.pdf.

Lorde, A. (2018b). As ferramentas do sinhô nunca vão derrubar a casa-grande (T. Nascimento, Trad.). https:// traduzidas.wordpress.com/

Maingueneau, D. (2005) Gênese dos discursos. (S. Possenti, Trad.). Criar Edições.

Martins, M. A. P. (2010). As contribuições de André Lefevere e Lawrence Venuti para a teoria da tradução. Cadernos de Letras da UFRJ, 1(27), 59-72. http:// www.letras.ufrj.br/anglo_germanicas/cadernos/numeros/122010/textos/cl301220100marcia.pdf

Mathias, A. (2017). Traduções transgressoras: a importância da tradução não oficial social de textos de autoria negra para o ambiente acadêmico. Translatio, 1(13), 215-233. https://seer.ufrgs.br/translatio/article/ view/71539

Mbembe. A. (2018) Crítica da razão negra. (1. ${ }^{a}$ ed.; S. Nascimento). $\mathrm{n}-1$ edições.

Nascimento, T. (2014) Letramento e tradução no espelho de Oxum: teoria lésbica negra em auto/re/conhecimentos. (Tese de doutorado), Departamento de Tradução, 
Universidade Federal de Santa Catarina, Florianópolis, Brasil.

Nascimento, T. (2017). Quem nomeou essas mulheres "de cor”? políticas feministas de tradução que mal dão conta das sujeitas negras traduzidas. Translatio, 1(13), 127-142. https://seer.ufrgs.br/translatio/ article/view/71586

Rocha, D. (2006). Representação e intervenção: produção de subjetividade na linguagem. Gragoatá, 1(21), 355-372. http://periodicos.uff.br/gragoata/article/ view/33231/19218

Secretário da Cultura copia discurso de ministro de Hitler e gera polêmica [versão eletrônica].
(17 jan. 2020). Deutsche Welle. https://www. dw.com/pt-br/secret\%C3\%A 1 rio-da-culturacopia-discurso-de-ministro-de-hitler-e-gerapol\%C3\%AAmica/a-52040824

Silva, D. A. (2014). De epistemicídio, (in)visibilidade e narrativa: reflexões sobre a política de representação da identidade negra em Cadernos Negros. Ilha do desterro, 1(67), 51-62. https://doi. org/10.5007/2175-8026.2014n67p51

Silva-Reis, D., e Amorim, L. (2016). Negritude e tradução no Brasil: O legado do Barão de Jacuecanga. Cadernos de Literatura em Tradução, 1(16), 7-18. http://www. revistas.usp.br/clt/article/view/115265/112950

Como citar este artigo: Calixto, R.; Peixoto, L. A.; Silva, L. M.; Giorgi, M. C. (2021). "As ferramentas do sinhô nunca vão derrubar a casa grande": análise discursiva de uma tradução marginal. Íkala, Revista de Lenguaje y Cultura, 26(2), 421-435. https://doi.org/10.17533/udea.ikala.v26n2a03 